\title{
A SUGESTÃO DE EQUILÍBRIO E AJUSTAMENTO EM KEYNES"
}

Wagner Nóbrega ${ }^{\text {** }}$

\section{APRESENTAÇÃO}

Desde que suas obras começaram a ser publicadas, John Maynard Keynes tornou-se senão referência, pelo menos um fermento no "caldo de cultura" do Pensamento Econômico.

No ano do sesquissagésimo aniversário daquela que é considerada a obra principal de Keynes - a Teoria Geral - tantas já são as proposições que se formaram, seja a partir da discussão sobre considerações keynesianas confrontadas com outras de teorias diferentes, seja da burilação do conteúdo da Teoria Geral, que se pode identificar a aparição de grupos distintos de pensamentos em função da teoria keynesiana, que se constituíram correntes do pensamento econômico, diferenciadas conforme as afinidades distintas sobre temas e óticas que cada uma delas enfatiza como sendo de importância no tratamento das questões de Teoria Econômica.

\footnotetext{
Agradeço ao colega Robério Ferreira dos Santos pelo incentivo moral e o acesso a parte da bibliografia, sem a qual o presente artigo não seria concretizado.

** Professor auxiliar substituto do curso de Economia da Universidade Federal da Paraiba Campus II. Mestrando do Curso de Economia do Trabalho da UFPB - Campus I
} 
O presente artigo é uma sistematização de uma parte dessa "árvore genealógica" com que pode ser representado hoje o Pen. samento Econômico com relação a Keynes, tratando das principais teorias que dão ênfase aos aspectos de equilíbrio geral e de ajustamento como característicos da teoria de Keynes ${ }^{1}$, quais sejam a bordagem IS - LM, a consideração dos efeitos do real cash balance e da preferência pela liquidez para o equilíbrio e ajustamento da economia através de variações nos preços, e o ajustamento através das quantidades, as quais compõem a estrutura básica da Sintese Neoclássica.

Não se pretende com a sistematização em questão, esgotar a discussão sobre diferenças e afinidades entre a teoria keynesiana e essas suas abordagens. $O$ que se pretende é, apenas, destacar a importância do pensamento keynesiano no conjunto do pensamento econômico, usando-se, para tanto, de um exemplo ao tratar de uma das correntes mais divulgadas desse pensamento.

O tema é apresentado em cinco seções. A primeira é uma proposta de caracterização da teoria keynesiana. Da segunda à quarta, são apresentadas as principais teorias de abordagem da Teoria Geral da corrente da Síntese Neoclássica e comentadas à luz do tratamento dos principais postulados que caracterizam a teoria keynesiana, conforme derivados da caracterizaçäo apresentada na primeira parte. Na última seção, se encontram as nossas considerações finais.

\section{A TEORIA DE KEYNES.}

Caracteriza, fundamentalmente, a teoria keynesiana, a preocupação explicitada na Teoria Geral, em explicar o sistema econômico com plausibilidade nos fatos da experiência da sociedade econômica de sua época, uma vez que considera que as proposições "clássicas" não são pertinentes aos fenômenos de então. São, pois,

\footnotetext{
${ }^{1}$ Para fins de simplificação, caracterizaremos a teorla keynesiana com base, tâo somente, na leitura da Teoria Geral. Assumimos, com isso, os riscos de deixar de considerar contribuiçðes presentes principalmente em outras obras.
} 
os sentidos de atualização e aplicabilidade - não-empiricista - que norteiam a chamada "Revolução Keynesiana". Neste sentido, o primeiro capítulo da Teoria Geral é revelador daquilo que Victoria Chick considera como sendo a teoria de Keynes uma "abstração pertinente" .

No capítulo 18, ao justificar a escolha das variáveis que considera para estudo, Keynes revela ter se abstido de analisar e de levar em consideração as conseqüências das variações das seguintes: (Keynes: 1988, p. 191)

[a] capacidade e quantidade de mão-de-obra disponível, o estado da técnica, o grau de concorrência, os gostos e hábitos dos consumidores, as desutilidades das diferentes intensidades de trabalho e das atividades de supervisão e organização, bem como a estrutura social, incluindo as formas que determinam a distribuição da renda nacional.

Uma vez desconsideradas essas variáveis, a teoria keynesiana trata de explicar a possibilidade de a demanda ser insuficiente em relação àquela para a qual os empresários decidiram seus níveis de produção ${ }^{3}$, o que é conhecido como o problema da demanda efetiva. Tratemos de tal problema.

A demanda efetiva para Keynes é equivalente ao volume de negócios realizados na economia em cada período, a um nível de preços respectivo. Para o fechamento de tais negócios oferta e demanda de toda a economia - respectivamente chamadas de oferta e demanda agregadas - são confrontadas.

A oferta agregada é o volume de produção decidido pelas firmas, quando esperam maximizar lucros, para receitas esperadas dependentes do nível de preços esperado e custos calculados com base na combinação de um certo volume de trabalho empregado (que, a nível agregado, é o nível de emprego) com os insumos para

${ }^{2}$ Chick, Victoria. Macroeconomia após Keynes. Rio de Janeiro: Forense Universitária, 1993.

${ }^{3}$ Lima (1992, p. 15) considera como tipicamente keynesiana a preocupação de saber como a teoria econômica contemporânea explica os níveis de produção e do emprego a partir da inevitabilidade do desemprego involuntário em economias tipicamente capitalistas. 
as condições técnicas prevalecentes. Na representação de tais cus" tos, Keynes considera todos eles em relação à unidade de trabalho, medindo para esta unidade não só os salários nominais, como também a proporção dos "outros elementos de custo" que lhe são correspondentes ${ }^{4}$.

Do que foi dito acima, a oferta agregada pode ser representada algebricamente da seguinte forma: $Z=((\mathrm{N})$, sendo $\mathrm{Z}$ o nível de preços esperado pelos ofertantes para o volume de produção $[((\mathrm{N}))]$ e o nível de emprego (N) respectivos.

A demanda agregada na forma como acontece na atividade econômica, é composta por uma parte de demanda por bens de consumo e outra de bens de investimento. Ela pode ser representada como a estimada pelo agregado das firmas da economia para um dado volume de emprego e renda correspondentes. Tomando esse ponto-de-vista, Keynes representa a demanda agregada da seguinte forma: $D=f(N)$, sendo $D$ o nível de preços ao qual a demanda deseja adquirir a produção resultante de $\mathrm{N}$.

Contudo, a demanda efetiva, ou aquela que de fato acontece na atividade econômica, não necessariamente é tão grande quanto a esperada pelas firmas ao definirem'a representação desta demanda.

Pode acontecer que ao nível de renda resultante de um determinado nível de emprego, as pessoas desejem comprar menos produto do que o ofertado, ou dito da forma de Keynes, que o nível de preço esperado pela oferta (Z) é maior do que o que de fato a demanda aceita $D$, significando que a oferta superestimou a demanda.

O desacompanhamento da atividade econômica de demanda, ou demanda efetiva, em relação. à sua estimação é explicado por Keynes pelo fenômeno da propensão marginal a consumir, que faz com que o desejo de demanda por bens de consumo aumente sem. pre menos do que a renda. Com a atuação deste fenômeno, se a oferta estivesse em um nível estabelecido para uma maximização

\footnotetext{
4 “... o salário nominal c os outros elementos de custo permaneçam constantes por unidade de trabalho..." (Keynes: 1988, p. 39).
} 
de lucros cujas receitas previam um nível de renda resultante de determinado nível de emprego que acaba não confirmando tais receitas, os produtores de bens de consumo acabariam teriam, no imediato, uma perda correspondente às receitas não confirmadas. Para compensar tal perda a firma teria de desempregar até atingir o nível de produto desejado pela demanda. Com isso, o equilíbrio entre a oferta e demanda efetiva aconteceria a um nível inferior daquele esperado pelos ofertantes quando da representação da demanda agregada, de modo que seria possível oferta e demanda estarem equilibradas com desemprego involuntário, visto que a tal nível de equilíbrio a oferta teria capacidade de empregar mais, mas não o faz por conta da deficiência da demanda.

Para que a economia atingisse um equilíbrio automático entre oferta e procura, portanto, seria necessário que coincidisse de ao mesmo tempo em que a demanda por bens de consumo se mostrasse insuficiente, a demanda por bens de investimentos tivesse aumentado antes no montante suficiente para cobrir a diferença entre a demanda efetiva e a esperada. Com isso, para aumento da renda, o emprego teria de ser distribuído mais que proporcionalmente para a indústria de bens de capital do que para a de consumo, no montante exato para compensar a queda não prevista do consumo. Só neste caso circunstancial não haveria desemprego involuntário, ou, se já houvesse, tal desemprego não aumentaria.

A explicação feita do problema da demanda efetiva circunscreveu-se a uma abordagem estática da atividade econômica, de modo a evidenciar, tão somente, a diferença entre níveis de demanda esperado e efetivo em cada momento. Passaremos a des. crever, rapidamente, o processo que compreende não só uma daquelas comparações momentâneas, como também todas elas.

Para Keynes, uma vez que os empresários contratam trabalhadores esperando a maximização dos lucros, definida na maior diferença entre as receitas esperadas e os custos correntes de produção, à favor das receitas, e sendo o nível de produção o resultado da combinação do nível de emprego assim definido sob as condições físicas existentes de produção - que incluem a tecnologia tanto o nível de produção, quanto o de emprego dependem das expectativas dos empresários. 
Depois de definido o nível de produção, caso essas expectativas não se confirmem, deve, em conseqüência, cair o nível de emprego, independentemente de os trabalhadores aceitarem se empregar a salários mais baixos. Não existindo expectativas de vendas futu* ras que maximizem os lucros como esperados ${ }^{5}$, não haverá emprego, caracterizando-se, com isso, a possibilidade de permanência do desemprego involuntário.

São, portanto, o papel passive do emprego com relação às decisões dos empresários e a possibilidade da insuficiência da demanda perpetuar-se, que caracterizam a teoria keynesiana.

Depois de assim sugerida como problema econômico, a demanda efetiva, é explicada em função da relação entre os níveis de emprego, dos investimentos, da renda e da taxa de juros. Passaremos a tratar dessas relações.

As expectativas de longo prazo sobre os retornos futuros dos bens de capital que o agregado dos empresários - que passaremos a chamar de empresariado ${ }^{6}$ - resolve acrescentar às capacidades produtivas de suas firmas, juntamente com os preços dos mesmos bens de capital, determinam a taxa de eficiência do capital, ou eficiência marginal do capital.

A teoria keynesiana se caracteriza pela consideração da incerteza, que está relacionada com a impossibilidade de se garantir no futuro rendimentos obtidos no presente ou esperados de se obter. Em tal quadro, a moeda assume um papel fundamental. Pela combinação de suas características de reserva de valor e meio de troca, ela é a mais confiável para garantir hoje comando sobre consumo ou rendimentos futuros. Por isso, a moeda tem atratividade própria, ao que se chama de preferência pela liquidez. Es-

\footnotetext{
${ }^{5}$ Correspondem aos incentivos a investir. A possibilidade de pouco incentivo a investir é sugerida por Keynes, considerando-se os fatores de aumento do risco que se segue ao aumento das incertezas, causado, por exemplo, pelo fato de que a propensão a consumir de uma população tende, segundo Ḱeynes, a ser menor quanto maior a renda da nação.

${ }^{6}$ A agregação keynesiana supõe o conflito entre as decisø̃es de planejamento e de efetivo dos agentes, de modo que o agregado não é o somatório das decisðes individuais, mas a solução daqueles conflitos, que raramente tem em poucos agentes individuais uma representação perfeita.
} 
tando a preferência pela liquidez relacionada à troca e à especulação, principalmente, a demanda por moeda pode ser considerada como sendo composta por uma parte para transação e outra para especulação. Saliente-se que todos os ativos que assumirem essa propriedade, de reserva de valor facilmente conversível em meio de troca, são considerados substitutos próximos da moeda e devem constar no cálculo da mesma, conforme seus graus de convertibilidade ou liquidez.

Conforme for pessimista ou otimista a resultante das expectativas de curto e de longo prazos, o estado de confiança na economia correspondente a cada resultante dessas expectativas aponta, respectivamente, positiva e negativamente para a preferência pela liquidez para especulação, aumentando, assim, a demanda por moeda em sua componente de especulação.

Se o estado de confiança é baixo, a preferência pela liquidez alta faz com' que se aumente a demanda monetária na sua parte de especulação.

A demanda monetária, confrontada com a oferta monetária, determinam a taxa de juros.

Sendo o investimento uma decisão relacionada com o longo prazo, ele acontece como resultado da comparação entre a eficiência marginal do capital com a taxa de juros.

Estando baixo o estado de confiança, e mantendo-se constante a oferta monetária, ou não crescendo na mesma proporção da demanda, as taxas de juros se tornam altas relativamente à eficiência marginal do capital, o que reflete o pouco incentivo a investir do empresariado. Diz-se que "reflete", porque quanto maior a incerteza do empresariado, maior será a taxa de juros, caso se mantenha constante a oferta monetária, um vez que aquela incerteza se reflete na maior demanda por moeda, dada a preferência pela liquidez. Portanto, é o grau de incerteza do empresariado, resultante de sua expectativa, que determinam o investimento.

$\mathrm{O}$ investimento, relacionado à propensão a poupar da população, via multiplicador, determina o nível da renda e, dadas as condições físicas da oferta para tal nível de renda, do emprego. Assim sendo, são as variações do nível de investimento que de- 
terminam as flutuações do nível do produto e do emprego. Cabe considerar que a propensão a consumir, cujo inverso é a propensão a poupar, depende negativamente do nível da renda (riqueza) de uma população.

Do que vimos acima, depreende-se que, a dinâmica de Keynes pode ser entendida através de sua teoria da determinação da renda, e que esta teoria é composta, fundamentalmente, por uma teoria do investimento, uma teoria da moeda e uma teoria da taxa de juros.

Diante de flutuações da renda e do emprego respectivo, a moeda assume um papel ativo, à medida que se sua oferta for exógéna, o aumento dela, por exemplo, pode compatibilizar-se com o aumento da demanda monetária, quando, tendo crescido sua desconfiança na economia, a preferência pela liquidez do empresariado é elevada. O resultado de tal compatibilização é a manutenção possível da taxa de juros ao nível anterior ao do aumento da demanda monetária. Portanto, fica sugerida a possibilidade de manipulação da taxa de juros, caso a política monetária seja ativa.

Contudo, sendo a política monetária restrita aos fenômenos de curto prazo, e estando as decisões de demanda monetária da comunidade como um todo permeadas pela incerteza com que se relacionam as decisões do presente com as expectativas de futuro, a eficácia da política monetária apenas por um acaso será obtida.

$O$ alcance da teoria de Keynes pode ser entendido como sugerido por O'Dennell [Lima (1992, p. 26) ]:

1) o fato de ser ela uma teoria do produto como um todo;

2) sua compatibilidade com a existência de um espectro variado de níveis de equilíbrio de emprego, enquanto a ortodoxia permanecia confinada ao equilíbrio ao pleno emprego; e

3) sua aplicabilidade a todas as circunstâncias sob as quais pudesse ocorrer a produção capitalista.

\section{A SíNTESE NEOCLÁSSICA.}

A denominação de "Síntese Neoclássica", é mencionada por 
Hicks para designar uma escola que se estava formando a partir de suas considerações no Value and Capital, e cujos fundadores eram Samuelson, Arrow, Friedman e Don Patinkin, como nos chama a atenção Franco [Almeida (1988)].

As idéias contidas na obra inspiradora dessa corrente do pensamento econômico têm por fundamento o modelo IS-LM, que aparece pela primeira vez no artigo "O Sr. Keynes e os Clássicos" de Hicks, apresentado em 1936 numa reunião de Oxford da Sociedade Econométrica. Partiremos, pois, deste artigo para descrever os traços fundamentais dessa escola.

\subsection{O instrumental IS-LM.}

Na primeira parte de seu artigo, Hicks se lança à tarefa histórica de sistematizar aquilo que seria o sistema da teoria chamada por Keynes de clássica, para em seguida discutir as possíveis contribuições keynesianas da Teoria Geral.

A descrição hicksiana da estática clássica é composta por três equaçôes fundamentais: $\mathrm{M}=\mathrm{kI}, \mathrm{Ix}=\mathrm{C}$ (i) e $\mathrm{Ix}=\mathrm{S}$ (i, I), sendo $\mathrm{M}=\mathrm{kI}$ a equação quantitativa de Cambridge, para $\mathrm{I}=$ renda total; $\mathrm{Ix}=$ renda ganha no setor de bens de investimento ou demanda por investimento; $\mathrm{S}=$ poupança; $\mathrm{e} \mathrm{i}=$ taxa de juros. A primeira equação nos indica que sendo conhecida $\mathrm{k}$ para um estoque de moeda dado, encontra-se a renda total. A segunda equação indica a dependência do montante do investimento em relação à taxa de juros, enquanto a terceira representa a identidade de gastos com investimentos e poupança. A combinação das três últimas equações nos demonstra o caráter real da taxa de juros, uma vez que a poupança deve ser entendida como adiamento de consumo. Assim, para uma dada taxa de juros e volume de poupança respectivo, chega-se à renda do investimento.

Se supusermos depreciação total do estoque de equipamentos da economia no período precedente à compra dos bens de investimento, uma vez determinado o volume de bens de capital da economia e sendo dada sua função de produção e a distribuição funcional da renda, o volume de emprego nos setores de bens de consumo e de investimento acaba sendo encontrado. 
Em função dessa estática, Hicks descreve a dinâmica clássica como sendo explicada a partir de variações em $\mathrm{M}, \mathrm{k}$ ou da distribuição de rendas. É da discussão dessas causas das flutuações que surge o que para Hicks vai caracterizar a teoria keynesiana. Portanto, a Teoria Keynesiana surge no artigo de Hicks em confronto com a dinâmica clássica, o que evidencia a identificação feita por Hicks da Teoria Geral com uma teoria de dinâmica econômica. Passaremos a tratar dessas relações de dinâmica.

A tentativa de explicação das flutuações industriais por via da variação de $M$ poderia ser frustada por uma série de dificuldades, segundo o autor tratado, porque sendo variação do empréstimo bancário, e estando os bancos propensos a emprestar, seria necessário se conhecer os determinantes do volume de crédito necessário para baixar a taxa de juros, bem como os elementos definidores do prazo de vigência desta queda, ou, o que dá no mesmo, do processo de elevação de preços aumentando o desconto bancário (determinando, assim, o fim da vigência daquela queda da taxa de juros).

Por outro lado, é possível entender-se as flutuações através da observação da ação do comportamento dos agentes em relação à taxa de juros, manifesto na constante marshalliana. Se o princípio marginal opera na manutenção de saldos líquidos, tornando igual, conforme citação de Lavington feita por Hicks (p. 365), os retornos da moeda com gasto em consumo, com manutenção da mesma e com taxa de juros líquida, pode-se encontrar nessa possibilidade, segundo Hicks, a "passagem" para o início da teoria keynesiana.

Keynes, segundo Hicks, teria inicialmente dado destaque ao tratamento da demanda monetária como estando, tão somente, em função da taxa de juros, o que significa mudar a primeira equação do sistema clássico para $M=L$ (i). Cabe observar-se que mesmo tendo considerado que também descarta-se qualquer influência da taxa de juros sobre a parte da renda poupada, mudando-se a terceira equação clássica para $\mathrm{Ix}=\mathrm{S}(\mathrm{I})$, acaba considerando esta "segunda emenda" como insignificante. A "primeira emenda" indica que, a um dado estoque de moeda, será determinada a taxa de juros e não mais a renda nacional. 
O esquema keynesiano assim composto acaba, em relação ao clássico, por independentizar a demanda por investimentos da determinação da taxa de juros. $O$ que explica a taxa de juros para um estoque dado de moeda é a preferência pela liquidez (L).

Os três principais componentes da preferência pela liquidez ocupam na análise hicksiana papéis diferenciados ao longo da explicação da dinâmica econômica. Tal diferenciação pode ser percebida relacionando-se o prazo da taxa de juros com os respectivos riscos. No curto prazo predomina o motivo precaução, porque o que prevalece é a maior ou menor comodidade em se manter moeda disponível. $O$ motivo especulação atuaria mais a longo prazo, à medida que, em contraste com a garantia de desconto do título no curto prazo, no longo prazo as condições de desconto seriam desconhecidas, o que possibilitaria ganhos sobre acertos e erros com taxas de juros contratadas. $O$ incremento do risco significaria, concomitantemente, a elevação dos custos de uso da moeda. Por isso, à medida que aumentam as taxas de juros, seguindo o aumento dos riscos ${ }^{7}$, diminui a demanda por moeda relativamente ao volume de transações. Em outras palavras, há uma tendência a que a taxa de juros aumente no longo prazo, enquanto a demanda por moeda aumenta menos que proporcionalmente à elevação do volume de transações. conseqüentemente, no curto prazo, quando se estabelecem as taxas de juros dos títulos, poderia haver uma taxa de juros suficiente, apenas, para remunerar a valorização na margem da moeda e do respectivo título, caso o motivo precaucional fosse mínimo. As implicações deste nível mínimo de taxa de juros para as quais Hicks nos chama a atenção podem ser percebidas depois que Hicks, considerando que Keynes teria montado a equação de $\mathrm{M}$ em função tão somente de i para fins de simplificação, e que ele mesmo, dentro do caráter geral de sua teoria, admitia a influência de outras variáveis, tais como o nível de renda,

\footnotetext{
${ }^{7}$ Por isso se pode dizer que, a abordagem nominal da taxa de juros das teorias dos fundos de empréstimo não é incompativel com o entendimento de Hicks sobre a taxa de juros, à medida que ele considera a taxa de juros de curto prazo (money rate of interest) como taxa de juros para aplicações financeiras, determinada no mercado de aplicações financeiras. Contudo, tal consideração significa, no mínimo, uma mudança no caráter desta taxa de juros, uma vez quc na teoria dos fundos emprestáveis essa taxa pode permanecer durante um prazo extenso.
} 
uma vez que o "motivo especulação" não pode aparecer numa economia desacompanhado do "motivo transação", passa a considerar $M=L(I, i)$, para $i$ estando inversamente relacionada com a demanda monetária e I diretamente relacionada com a mesma de. manda monetária, sendo que $i$ tende a aumentar à medida que cresce o produto, como uma representação possível da teoria "geral" de Keynes.

Com todas as combinações de pares de taxa de juros e volume de mercadorias transacionado na economia com os quais oferta e demanda monetária se igualam na equação $\mathrm{M}=\mathrm{L}(\mathrm{I}$, i), Hicks compõe a curva LM (originalmente chamada LL):

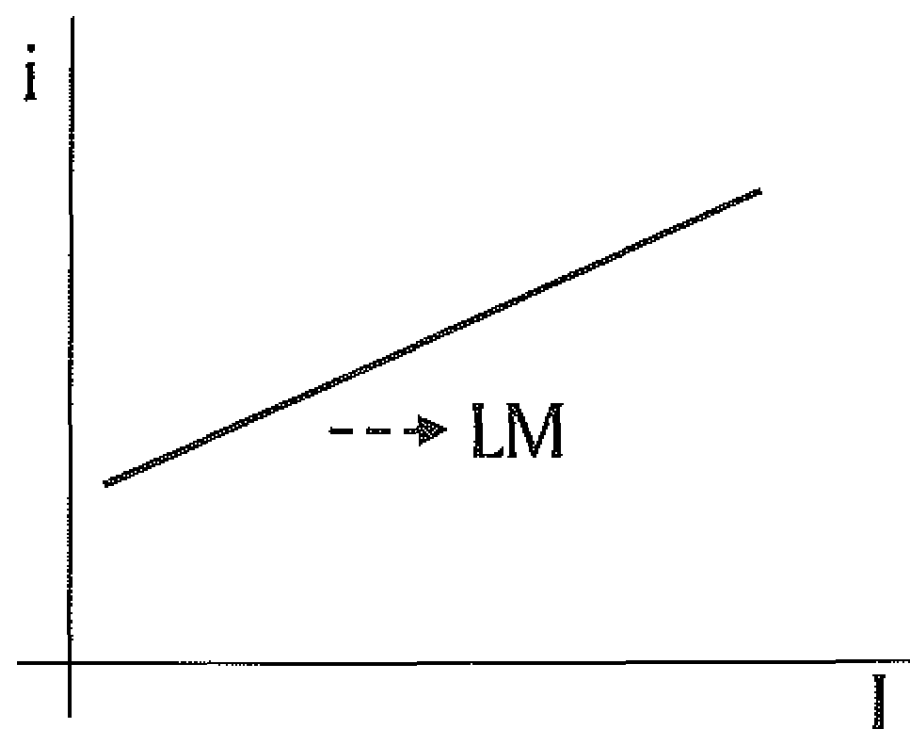

Observe-se que para que a curva LM seja escrita, é desconsiderado o efeito de variações na oferta monetária, de modo que "[...] uma dada oferta de moeda determina uma certa relação entre renda e juros" (Hicks: 1988, p. 368). Ou seja, cada curva LM é definida para uma oferta monetária fixa. Contudo nada impede que tal construção seja feita para taxas constantes de crescimento da oferta monetária ou crescimento da demanda monetária à frente da oferta monetária, uma vez respeitada a prioridade suposta por Hicks de que as autoridades monetárias interfiram no mercado da moeda apenas até o limite de não mudar a tendência nele determinado pelas forças de demanda e oferta de moeda năo governa- 
mentais:

Ao invés de admitirmos [...] que a oferta de moeda é dada, podemos supor que existe um sistema monetário dado - e que até certo ponto, mas apenas até certo ponto, as autoridades monetárias preferem criar uma nova moeda ao invés de permitir que as taxas de juros cresçam. Essa curva LL generalizada irá então inclinar-se apenas suavemente para cima, sendo que a elasticidade da curva dependerá da elasticidade do sistema monetário (no sentido monetário comum). (Hicks: 1988, p. 373 - grifo original)

À semelhança da abordagem das negociações com moeda em um mercado específico dito mercado da moeda, a abordagem das negociaçōes com o produto é feita considerando-se um mercado específico para tanto, o do produto. Desta feita, usam-se as duas outras equações, a saber, $I x=C$ (i) e $I x=S(I)$. A primeira equação indica o investimento para qualquer taxa de juros, via eficiência marginal do capital, enquanto a segunda indica o nível de renda para qualquer relação do investimento com o consumo, via multiplicador, que tornam iguais poupança e investimento. Uma vez que taxas de juros mais altas podem inibir o investimento, há uma relação inversa entre i e Ix, refletida no nivel do produto via multiplicador.

Da mesma forma que o da moeda, o mercado do produto é representado graficamente para todos os equilíbrios de taxa de juros e produto, desta feita para oferta e demanda de produto equilibradas. Tal representação é chamada de curva IS. Para encontrá-la, considere-se que se possa calcular a eficiência marginal do capital em termos monetários. Depois, sabendo-se que a taxa de juros resulta da oferta e demanda de moeda, sendo a primeira resultante de poupanças e a segunda da eficiência marginal do capital, para cada nível de taxas de juros contratadas no encontro de poupança com eficiência marginal do capital corresponderá um de investimento e, respectivamente via multiplicador, um de renda. Assim, a derivação da curva IS é obtida para diversos pares de investimento e poupança em equilíbrio. 

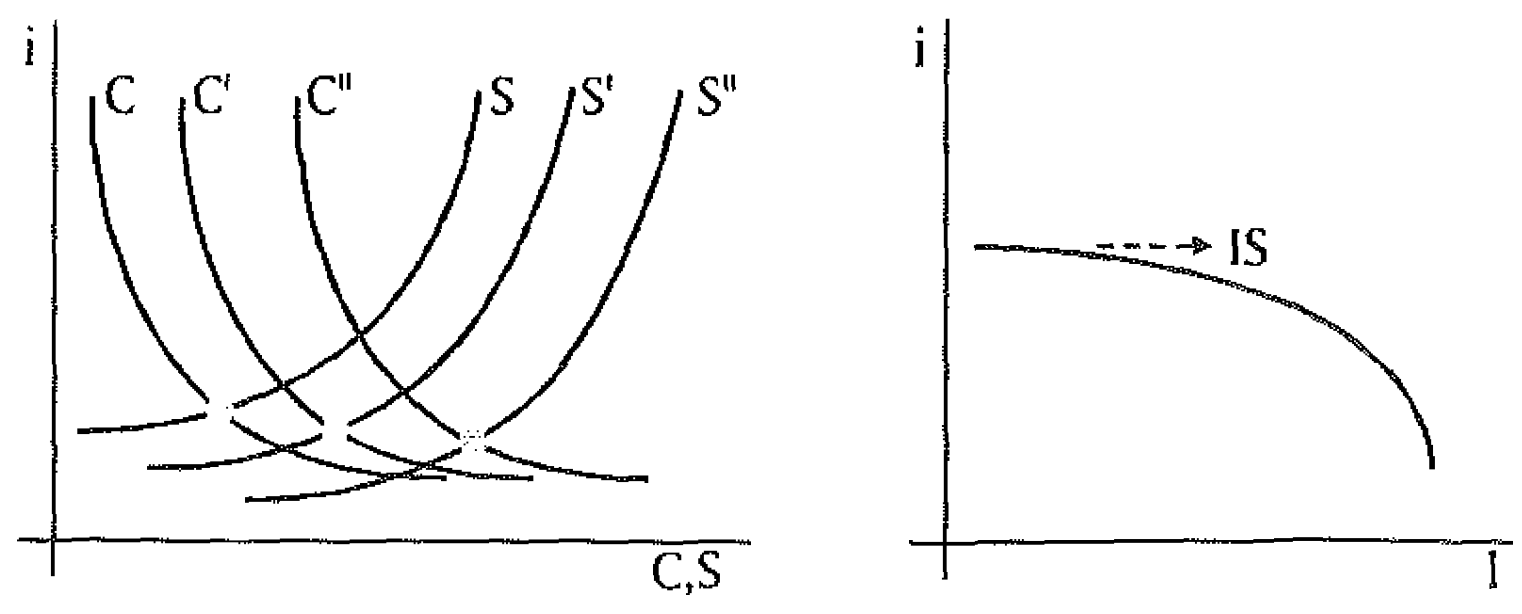

À medida que a renda aumenta, a curva de poupança (S) deve se deslocar mais do que a de eficiência marginal do capital (C). Com isso, os sucessivos equilíbrios de investimentos e poupança ao longo do crescimento da renda deve acontecer de forma a relacionar inversamente taxa de juros e renda.

Quando o nível de taxa de juros é o mais baixo possível, como tratado na página anterior, descreve-se na curva LM uma parte horizontal à esquerda. Isto corresponde à liberalidade com que os agentes deixarão à disposição a moeda, dado serem poucos os motivos que eles têm para demandá-la. Para este nível, quaisquer aumentos na eficiência marginal do capital, indicada por $\mathrm{Ix}=\mathrm{C}$ (i), significarão, para uma mesma propensão a consumir, um aumento na renda e no emprego, sendo o aumento da renda percebido na "segunda emenda", via multiplicador que relaciona a propensão a poupar inversamente com o investimento. Da mesma forma, dada a relação entre a propensão a consumir e o investimento, um aumento na primeira elevará o nível de produto e renda. Ambas as implicações do nível de mínimo da taxa de juros para a renda e o emprego são representados pela nova intercessão da curva IS com a LM depois de deslocada a primeira ao longo da parte horizontal da segunda.

$O$ domínio da preferência pela liquidez, portanto, se restringiria à recuperação e pico (aqui confundido com pleno-emprego), quando as pessoas preferem manter mais moeda, distribuindo-a para aumento de transação e por elevação dos riscos crescentes de 
desconto. Assim, a consideração keynesiana de que seria possível se aumentar a renda e o emprego sem que as taxas de juros sofressem alterações, diria respeito, tão somente, ao período de depressão. Disto, se conclui que para Hicks a teoria keynesiana em seu modelo simplificado representa uma complementação da teoria "clássica", visto que no movimento de expansão da renda e do emprego seus resultados são plenamente similares aos do pensamento marshalliano revisitado, quando a taxa de juros e a renda aumentam para aumentos no incentivo a investir - parte intermediária da curva LM - e à clássica, quando incentivos a investir maiores implicariam, apenas, aumentos na taxa de juros - parte vertical da curva LM. A teoria keynesiana, é, portanto, entendida como perfeitamente compatível com a teoria clássica, sendo isto representado na seguinte curva $\mathrm{LM}^{8}$.

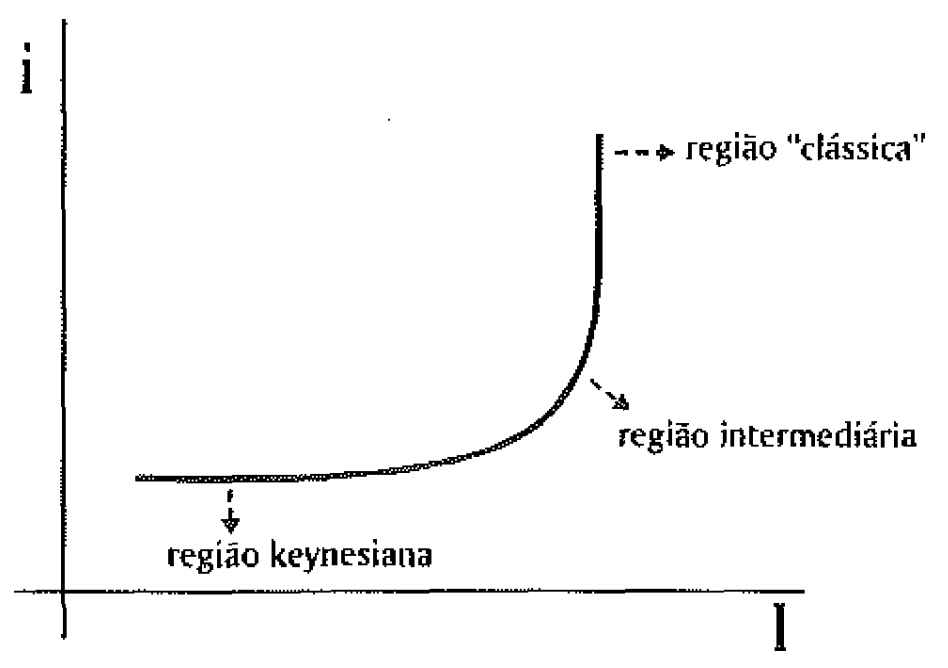

Uma vez que a teoria geral keynesiana apresentaria como novidade, do ponto de vista de Hicks, apenas a explicação da depressão, sendo perfeitamente substituível pela clássica ortodoxa - intercessões de IS com LM na parte vertical desta última - e pela clássica marshalliana revisitada - intercessões na parte intermediária da curva LM - entende-se que a teoria keynesiana é consi-

${ }^{8}$ Para Hicks, expansðes na oferta monetária deslocam a curva LM para a direita, de modo que a política monetária só é eficaz nas regiões intermediária e clássica. 
derada por Hicks como mera complementação da teoria clássica, restrita a um caso especial dela.

Além da restrição da teoria keynesiana a um aspecto complementar à "clássica", destaca-se da abordagem de Hicks a ênfase no caráter de equilíbrio geral e simultâneo, como condição da construção do instrumental IS-LM.

Como vimos, por um lado, os equilíbrios de oferta e demanda de moeda são representados por pares de taxa de juros e nível de produto, da mesma forma que também existem pares de taxa de juros e de nível de renda para representar cada equilíbrio no mercado do produto; por outro lado, a determinação do nível de renda da economia e da taxa de juros correspondente é feita para o equilíbrio dos mercados do produto com o da moeda, correspondente à intercessão da curva IS com a LM, de modo que sob tais taxas de juros e nível de renda estarão equilibrados cada mercado e a economia como um todo simultaneamente.

A premissa de equilíbrio geral e simultâneo é resguardada pelo mecanismo de ajuste automático de preços'. Observemos a figura abaixo.

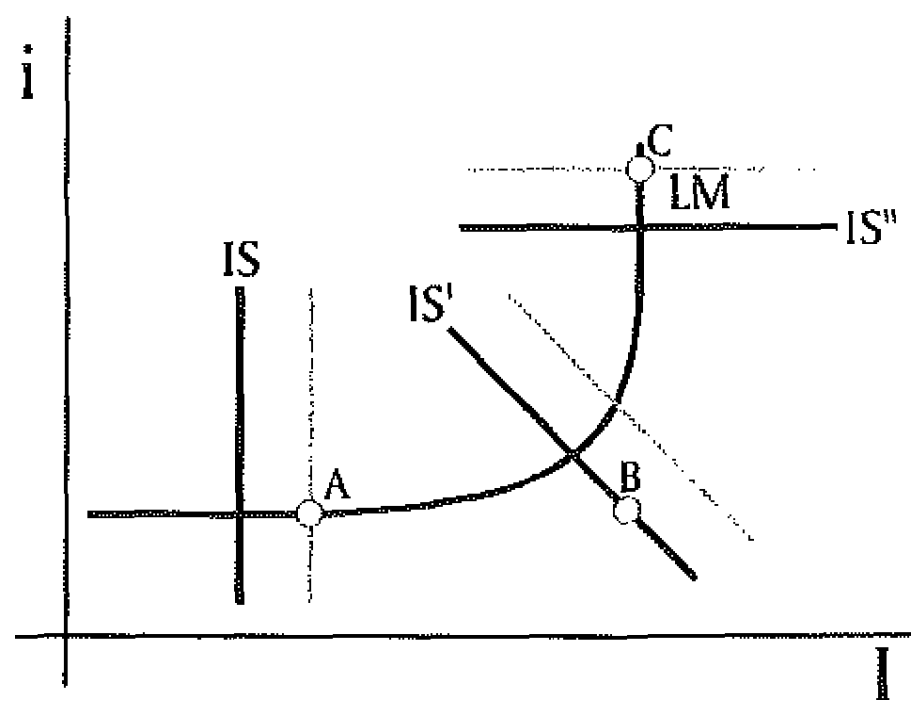

${ }^{9}$ Inclusive da taxa de juros, considerada preço de adiamento do consumo. 
$\mathrm{Na}$ figura acima ${ }^{10}$, observa-se o caso de expansão do emprego e da renda, ao longo da curva LM, para a direita. Neste esquema hicksiano, considera-se a remuneração do trabalho pelo seu custo marginal, e os preços das mercadorias expressos em salários. Os pontos $\mathrm{A}, \mathrm{B}$ e $\mathrm{C}$ representam, respectivamente desequilíbrios entre o mercado do produto e da moeda, enquanto as retas mais claras representam o reajuste do equilíbrio da economia. Na depressão, se os empresários decidem investir no ponto $\mathrm{A}$, as taxas de juros muito baixas permitem a venda de um volume maior de títulos no mercado, enquanto o elevado nível de desemprego garante a estabilidade dos preços. No ponto $B$, quando a economia está se recuperando, se acontecer de a taxa de juros ser menor do que a desejada para a produção, o aumento da produção será seguido do aumento da taxa de juros, uma vez que há inflação por conta de a firma transmitir para um novo vetor-preço os salários aumentados, dada a raridade do fator trabalho que começa a acontecer. $\mathrm{Na}$ região de recuperação, portanto, aumentos na renda são acompanhados de aumentos na taxa de juros. No ponto $C$, não há mais trabalho disponível e a disputa pelo já existente fará com que as firmas paguem salários maiores, o que com preços flexíveis como suposto até agora, se transformará em um novo vetor preço através da inflação. Neste caso, não haverá aumentos da renda, apenas da taxa de juros ${ }^{11}$.

Em resumo, o emprego crescente ao longo da curva LM para a direita é acompanhado por elevação do nível de preços, que é compensado na taxa de juros. $O$ aumento nos preços equilibra o mercado do produto, enquanto o na taxa de juros equilibra o da moeda. A compensação mencionada, por sua vez, equilibra o mercado do produto com o da moeda, conseqüentemente, torna a economia equilibrada, ou seja ajusta a economia.

A conseqüência de se ter o mecanismo-preço como instrumento

\footnotetext{
10 A inclinação da curva IS ao longo da LM "de longo prazo" é explicada por Hicks em função dos avanços da eficiência marginal do capital relativamente aos da poupança, para cada região da figura apresentada. Para maiores detalhes, ver as páginas $156 \mathrm{e} 157$ do artigo tratado.

11 Note-se gụe a dinâmica de ajustamento dos mercados via combinação de preços e taxa de juros segue uma ótica semelhante à wickselliana da taxa de juros.
} 
do tâtonnement walrasiano, é a desconsideração do papel das expectativas e incertezas, fundamentais no pensamento de Keynes para a explicação das instabilidades, em favor do ajustamento automático e simultâneo dos mercados e da economia. A interpretação hicksiana da teoria de Keynes, além disso, suprime qualquer análise de equilíbrio parcial marshalliano presente na Teoria Geral impondo o equilíbrio geral walrasiano, e introduz a departa mentalização na abordagem da economia, sobre o que existem sérias restrições.

\section{A CONTRIBUIÇÃo de DON PATINKIN.}

Patinkin, conforme ele próprio teria dito a Hicks, adotou o esquema hicksiano para desenvolver suas considerações. Antes, contudo, de tratarmos propriamente do modelo de Patinkin e de seu possivel significado para o pensamento econômico, cuidemos de apresentar os traços caracterizadores da abordagem por ele usada.

O tema central do trabalho de Patinkin são as forças monetárias vistas à partir do mercado de mercadorias, mais especificamente das transações $(1965$, xxiii).

Money buys goods, and goods do not buy money. The natural pla$c e$, then, to study the workings of monetary forces is directly in the markets for goods. This will be our central theme.

A adoção desse tema teria acontecido por conta de sua insatisfação com os approachs das transações que existiam antes de seu trabalho. Por um lado, segundo ele, aqueles baseados na teoria quantitativa da moeda não exploram as potencialidades do tema, porque restringem a explicação a um caso específico de demanda agregada independente da taxa de juros e diretamente proporcional à quantidade de dinheiro. ${ }^{12}$ Por outro lado, os approachs re- 
centes à sua época com base nas teorias monetárias se desviam do centro de ênfase do mercado de mercadorias para enfatizar o de moeda, usando para tanto o instrumento da descrição da função demanda por moeda. Patinkin considera que esta afirmação que "goods buy money", apesar de ser logicamente possível e ser prova de liberdade semântica, acontece porque aquelas teorias erram na forma como explicam a função demanda por moeda.

Além disso, apesar da equação neoclássica de cash-balance explicar com rigor os gastos de dinheiro com relação ao mercado de bens e da equação keynesiana (hicksiana) da preferência pela liquidez explicar a relação entre o mercado de títulos e os gastos, nenhuma das duas explicações aparecem sistematizadas nas equações monetárias de suas respectivas teorias, o que, por sua vez, implica na desconsideração de seus efeitos sobre os respectivos modelos.

As ausências da consideração do cash balance em relação aos bens e da preferência pela liquidez em relação aos títulos, combinadas com a restrição analítica da equação quantitativa da moeda e da ênfase no estudo de apenas um dos mercados da economia, compõem o problema que leva Patinkin a objetivar formular um novo modelo que contemple os efeitos das mudanças monetárias sobre todos os mercados da economia.

\subsection{A formulação de Patinkin}

Considerando que todas as teorias têm em comum as mesmas técnicas analíticas para as mesmas funções-demanda de mesmos mercados ${ }^{13}$, Patinkin estuda todos os mercados principais da economia com instrumental hicksiano de departamentalização da economia, tentando observar os efeitos das mudanças monetárias sobre os mercados da economia, o que o leva à consideração de

tendimento da determinação do nivel de preços do lado da demanda agregada por mercadorias (MV), conforme a teoria quantitativa da moeda $(\mathrm{MV}=\mathrm{PT})$. O outro lado dessa determinação é a oferta de mercadorias (T).

${ }^{13}$ [...] we achieve an integration of monetary theory and value theory: the propositions of both theories are derived by applying the same analytical techniques to the same demand funtions of the same markets. (Patinkin: 1965, xxiv) 
que, em geral, existe uma interação dinâmica entre as variações do nível de preços no mercado de bens e as variações da taxa de juros no mercado de títulos.

Todas as mercadorias da economia são vistas como divididas em quatro categorias, trabalho, commodities ${ }^{14}$, títulos e dinheiro. Conforme o mercado competitivo no qual são transacionadas, temse a seguinte tipologia de mercado: mercado de trabalho, mercado de commodities, mercado de títulos e mercado de dinheiro. Em cada um desses mercados são definidos os preços e quantidades transacionadas das respectivas mercadorias, em função de uma relação de oferta e procura pelas mesmas. Assim sendo, Patinkin representa cada um com suas respectivas funções de oferta e de demanda individuais ${ }^{15}$, procurando encontrar preços e quantidades transacionadas das mercadorias respectivas. Trataremos da representação de cada um desses mercados e de seus equilíbrios e conseqüências.

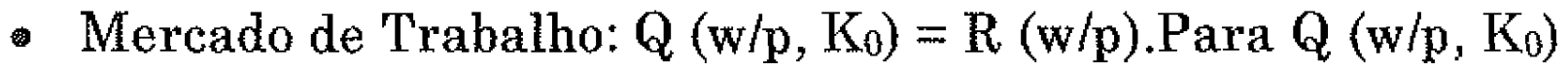
= demanda por trabalho e $\mathrm{R}(\mathrm{w} / \mathrm{p})=$ oferta de trabalho, sendo $K_{0}$ o estoque de capital, a demanda por trabalho uma função da produtividade marginal do trabalho $e$ $\mathrm{w} / \mathrm{p}=$ salário $\mathrm{real}^{16}$.

- Mercado de Commodities: $\mathrm{F}\left(\mathrm{Y}, \mathrm{r}, \mathrm{M}_{0} / \mathrm{p}_{0}\right)=\mathrm{Y}_{0}$.Para $\mathrm{F}\left(\mathrm{Y}_{0}, \mathrm{r}\right.$, $\left.\mathrm{M}_{0} / \mathrm{p}_{0}\right)=$ demanda por commodities ${ }^{17}$, e $\mathrm{Y}_{0}=$ oferta de commodities de pleno-emprego, sendo $\mathrm{Y}=$ renda real, $\mathrm{r}=\mathrm{taxa}$ de juros $\mathrm{e} \mathrm{M}_{0} / \mathrm{p}_{0}=$ real money (ou cash) balances.

- Mercado de Títulos: rp. $\mathrm{H}\left(\mathrm{Y}_{0}, 1 / \mathrm{r}, \mathrm{M}_{0} \mathrm{H} / \mathrm{p}\right)=\mathrm{rp} \cdot \mathrm{J}\left(\mathrm{Y}_{0}, 1 / \mathrm{r}\right.$, $\left.\mathrm{M}_{0}{ }^{\mathrm{F}} / \mathrm{p}\right)$. Para $\mathrm{rp} . \mathrm{H}\left(\mathrm{Y}_{0}, 1 / \mathrm{r}, \mathrm{M}_{0} \mathrm{H} / \mathrm{p}\right)=$ demanda por títulos $\mathrm{e}$

${ }^{14}$ Compoem as commodities os bens de consumo e os bens de investimento.

15 "There is, however, no pretense of showing how this process of aggregation is actually carried out." (Patinkin: 1965, p. 200).

${ }^{16}$ Esta equação é derivada da identidade do salárió real com a produtividade marginal do trabalho: $w / p={ }_{N}\left(N, K_{0}\right)$.

${ }^{17}$ A demanda agregada é composta pela adição dos gastos dos agentes da economia, quais sejam familias, empresas e governo, supondo-se independentes os gastos do governo e que os gastos de familias com consumo de bens sejam determinados pelas mesmas variáveis que os gastos das empresas (investimentos). 
rp.J $\left(\mathrm{Y}_{0}, 1 / \mathbf{r}, \mathrm{M}_{0} \mathrm{~F} / \mathrm{p}\right)=$ oferta de títulos, sendo. $\mathrm{B} / \mathrm{rp}=$ preço unitário real do título.

Mercado de Dinheiro: p.L $\left(\mathrm{Y}_{0}, \mathrm{r}, \mathrm{M}_{0} / \mathrm{p}\right)=\mathrm{M}_{0}$.Para p.L $\left(\mathrm{Y}_{0}, \mathrm{r}\right.$, $\left.\mathrm{M}_{0} / \mathrm{p}\right)=$ demanda monetária e $\mathrm{M}_{0}=$ oferta monetária (suposta constante).

Para fins de simplificação, pode-se considerar que o mercado de trabalho se mantenha sempre equilibrado. Tal proposição é plausível com base em que qualquer variação no nível de preço é compensada por variação no mesmo sentido do salário - o que está representado em todas as funções demanda e oferta acima pela falta de índices em w e p-seja por pressão do excesso de demanda ou de oferta por trabalho. Com isto, os equilíbrios nos mercados de títulos e de commodities são suficientes para se entender o equilíbrio na economia, visto que, pela "lei de Walras" se todos os mercados com exceção do da moeda estiverem equilibrados, este também estará.

Um equilíbrio qualquer no mercado de commodities pode ser representado graficamente como abaixo.

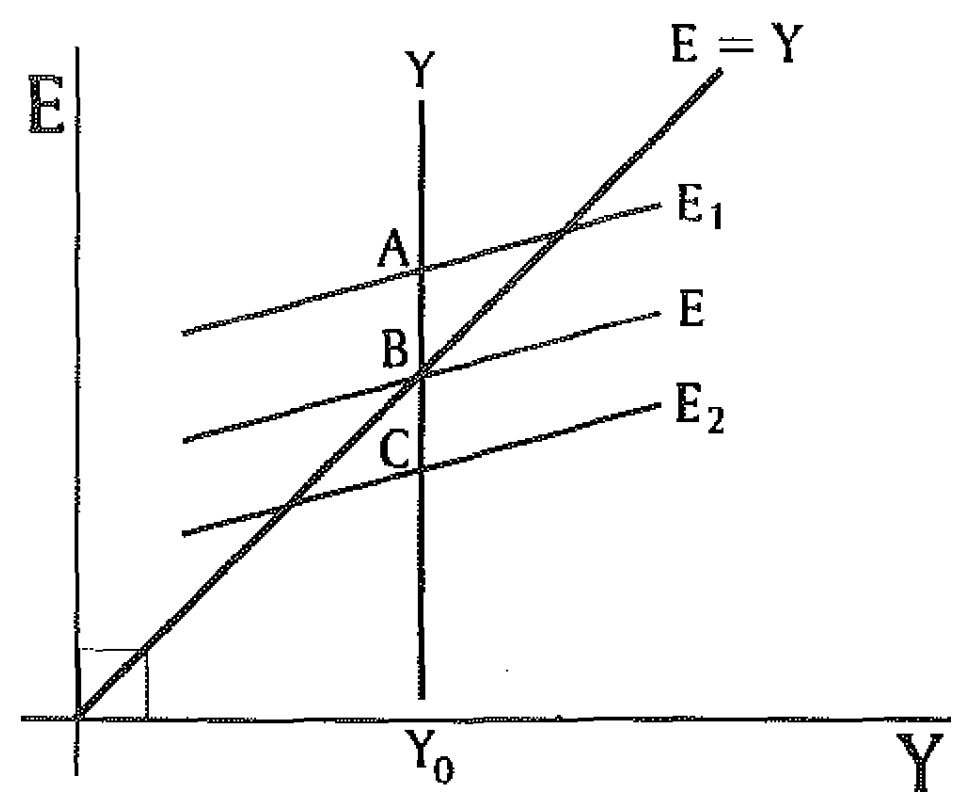

Se acontecer de os preços baixarem, no mercado de trabalho os salários nominais baixariam na mesma proporção, mantendo-se constante o salário real e, com isto, o equilíbrio do mercado de 
trabalho. O cash balance, contudo, aumentaria para um mesmo estoque de moeda, de modo a elevar a demanda por commodities ${ }^{\mathbf{1 8}}$, o que é representado pelo deslocamento de $E$ para $E_{1}$. $O$ ponto $A$ representa, portanto, um excesso de demanda em relação à oferta. Com isso, os preços se elevam, causando um aumento dos salários - conseqüentemente mantendo o equilíbrio do mercado de trabalho - e uma redução do real cash balance, o que traz de volta a curva de demanda ao ponto de equilíbrio anterior com a oferta (B). $A$ análise do deslocamento de $E$ para $E_{2}$ segue uma lógica semelhante, para o caso de uma alta nos preços, havendo, então um excesso de oferta em relação à procura, o que faz com que uma queda dos preços causada pela necessidade de diminuição dos estoques recomponha o equilíbrio. Assim, a proporcionalidade entre oferta e demanda de pleno emprego e seus ajustes inevitáveis formam a reta de quarenta e cinco graus, para os diversos equilíbrios no mercado de commodities ao longo do crescimento natural da economia.

O mercado de títulos, por sua vez, pode ser representado graficamente como abaixo.

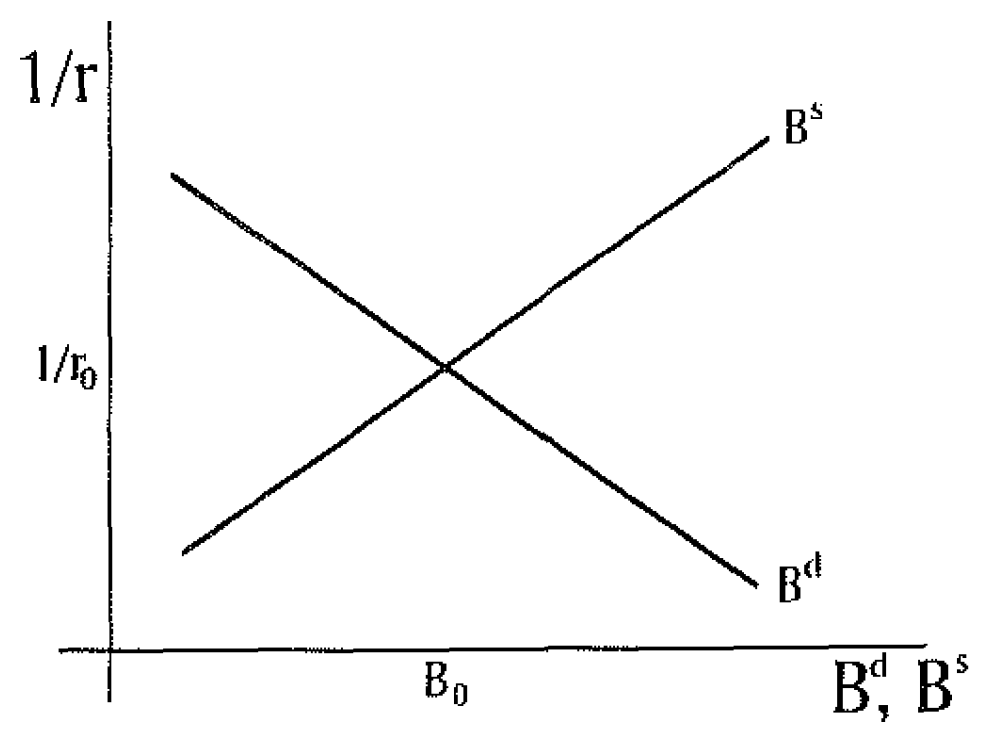

Para $\mathrm{Bd}=$ demanda por títulos e $\mathrm{B} s=$ oferta de títulos, sendo 
$\mathrm{B}_{0}$ equilíbrio das transações de títulos no pleno-emprego e $1 / \mathbf{r}_{0}=$ preço unitário do título no pleno-emprego.

Se, tudo o mais constante, a taxa de juros estiver acima ou abaixo da de equilíbrio ( $\left.\mathrm{r}_{0}\right)$, segue-se um ajuste semelhante ao que acontece no mercado de commodities. Para o caso dela estar abaixo, por exemplo, o preço dos títulos no mercado estão maiores do que a demanda desejava antes da queda da taxa de juros, criando um excesso de oferta de títulos em relação à demanda. Esse excesso faz com os ofertantes de títulos, concorrendo entre sí pelos escassos demandantes, elevem as taxas de juros de seus títulos, diminuindo, assim, os preços dos títulos. Isto restabelece o equilíbrio do mercado em $\left(\mathrm{B}_{0}, 1 / \mathrm{r}_{0}\right)$. Raciocínio semelhante é aplicado para o caso de uma alta nas taxas de juros, agindo, neste caso forças que elevam o preço dos títulos. Deste modo, o mercado de título tende a se manter equilibrado em $\left(\mathrm{B}_{0}, 1 / \mathrm{r}_{0}\right)$.

Do que foi dito sobre os mercados na economia, o sistema de Patinkin é dinamicamente estável para variações isoladas em r ou p.

Adotemos, agora, o esquema hicksiano para observar o equilíbrio simultâneo dos mercados e, conseqüentemente, da economia.

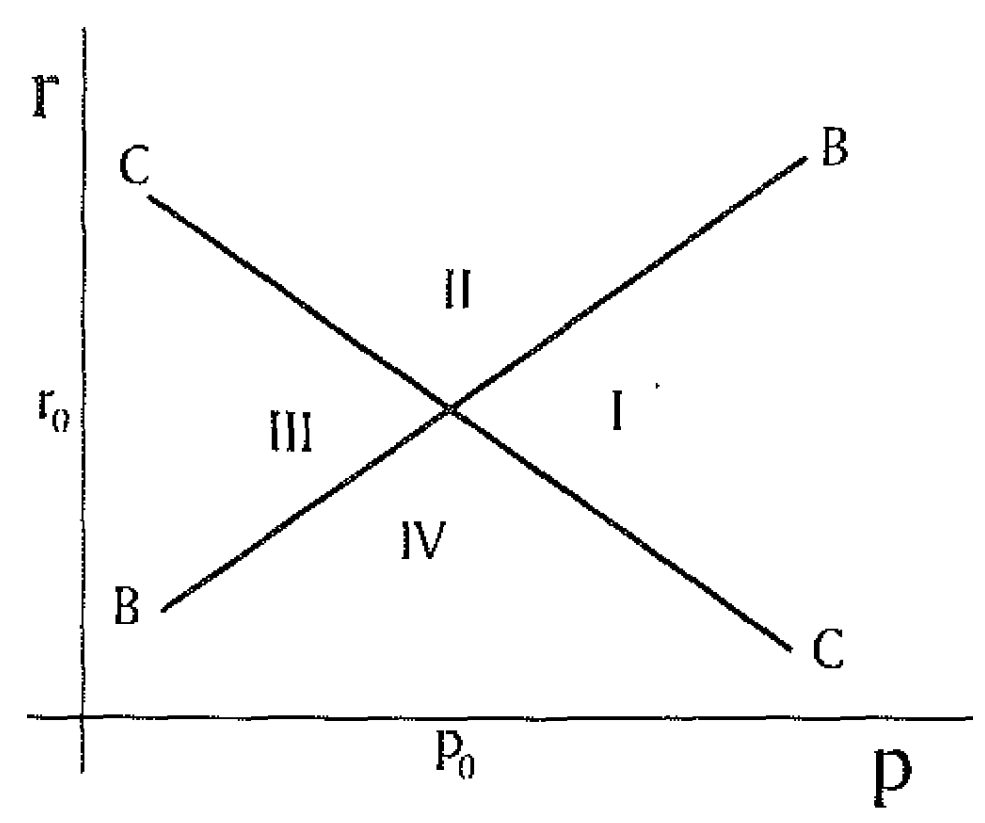


os pares de taxas de juros e preço que equilibram os mercados, podemos representar uma curva $\mathrm{CC}$, com relação ao mercado de commodities, e outra $\mathrm{BB}$, com relação ao de títulos, para mesmos eixos de taxas de juros e níveis de preços. A curva BB pode ser associada à LM de Hicks, bem como a curva CC pode ser associada à IS, como encontramos hoje na maioria dos manuais de macroeconomia.

$A$ inclinação positiva da curva $B B$ resulta da relação direta entre variações nos preços e variações nas taxas de juros de equilíbrio do mercado de títulos, uma vez que aumentos no nível de preços diminui o real cash balance dos demandantes de títulos, o que faz com que os que têm títulos para captar com eles recursos, ofereçam seus títulos a taxas de juros maiores. Por sua vez, a inclinação negativa da curva CC é explicada em funçäo de que aumentos na taxa de juros diminuem a demanda por investimentos, diminuindo, conseqüentemente, a demanda agregada. A causa da inclinação da curva $\mathrm{BB}$, nos permite identificar o efeito real money balance no mercado dos títulos, que demonstra como o mercado de commodities afeta o de títulos, enquanto a causa da inclinação da curva CC identifica o efeito da taxa de juros, que varia no mercado de títulos, sobre o mercado de commodities.

$O$ ponto $\left(\mathrm{p}_{0}, \mathrm{r}_{0}\right)$ indica o mesmo nível de preços e a mesma taxa de juros que equilibram cada mercado em separado, de modo que a economia está equilibrada. Tratemos de como acontece esta coincidência e simultaneidade. Para isto tomemos um caso.

Supondo inicialmente um desequilíbrio no mercado de commodities, representado por um ponto qualquer na primeira seção da figura acima, estaremos dizendo que está havendo excesso de oferta no mercado de commodities. Este excesso pressionaria a oferta de títulos no mercado de títulos elevando a taxa de juros, inibindo, assim, a demanda por investimentos. Ao final de sucessivas seqüências destas de ação e reação (tâtonnement) entre os mercados, o excesso de oferta será anulado e o ponto de equilíbrio da economia se restabelecerá em $\left(\mathrm{p}_{0}, \mathrm{r}_{0}\right)^{19}$. Da mesma forma, ha- 
verá para qualquer desequilíbrio em cada seção um processo de ajuste da economia ao equilíbrio anterior.

Por isto, o sistema de Patinkin é dinamicamente estável também para variações de $r$ e $p$, agindo estas variáveis para o equilíbrio inevitável da economia.

Por ter introduzido a discussão da teoria keynesiana dentro de um approach teórico walrasiano de longo prazo, no qual deve ser considerada a flexibilização de preços e salários, juntamente com os efeitos do real balance e da prefexência pela liquidez para todos os mercados da economia, o trabalho de $\mathrm{D}$. Patinkin teria significado uma sofisticação dos modelos ditos keynesianos de equilíbrio geral walrasiano. Por causa de tal flexibilização, o desemprego involuntário deixaria de existir no longo prazo, mesmo deixando-se de lado a suposição simplificadora de ajuste automático do mercado de trabalho. Assim, uma vez que os desequilíbrios presentes na teoria keynesiana aconteceriam, apenas, no curto prazo, o modelo de D. Patinkin reforçaria a defesa de que a Teoria Geral seria nada mais do que um caso especial da teoria clássica.

\section{O AJUSTAMENTO PELAS QUANTIDADES.}

As décadas de 60 e 70 foram épocas de conjunturas econômicas sob fortes choques de oferta.

Dada a incapacidade da Síntese Neoclássica em predizer o comportamento de preços e a produção nessa conjuntura de choques de oferta, o pensamento econômico da época caracterizou-se pela crítica à explicação da Síntese Neoclássica daqueles choques. Leijonhufvud e Crowel foram os primeiros formuladores das críticas à perfeição da informação e do ajustamento via preços por tâtonnement através do marketing clearing, presentes naquela teoria. Para esses autores, tal incapacidade se dava por ser a Síntese desprovida de fundamentos microeconômicos condizentes com o arcabouço propriamente keynesiano.

$O$ equilíbrio geral defendido por Patinkin era simultâneo e os preços se ajustavam para manter constante as quantidades transacionadas, caso oferta e demanda por bens de qualquer mercado 
variasse. Crowel defendeu um processo de ajustamento das quantidades, durante o qual o desequilíbrio era admitido. Para formular tal consideração, Crowel, segundo Tadeu Lima (1992, p. 62), teria partido de um problema encontrado e tratado por Patinkin, qual seja, que as firmas e famílias podem não conseguir transacionar a quantidade desejada nos mercados de bens e de trabalho ${ }^{20}$. A partir desta referência, os autores que tratam do ajustamento da economia através das quantidades se diferenciaram dos teóricos da Síntese, uma vez que o entendimento do desequilíbrio difere extremamente entre a abordagem desequilibrista e a da Síntese Neoclássica.

A explicação da Síntese Neoclássica, para as variações de quantidades é uma versão modificada do problema da demanda efetiva de Keynes, na qual este seria um fenômeno circunstancial, ao contrário de inerente para Keynes, e suas causas eram devidas a rigidezes no sistema econômico, tais como rigidezes de preços e salários, ilusões monetárias e fricções de mercado que levariam a demanda a ser deficiente. Tal deficiência se manteria caso o sistema de preços também estivesse deficiente, ou seja, existissem preços fixos. Com isso, as firmas não conseguiriam transmitir o novo vetor de marketing clearing que restabeleceria o equilíbrio e acabaria reduzindo a quantidade ofertada. Então, as famílias não poderiam adquirir a quantidade desejada ao nível de preço vigente. No caso de uma demanda deficiente, para a Síntese Neoclássica, portanto, a diminuição da oferta aconteceria por conta de inflexões temporárias no sistema econômico, seguida da diminuição da demanda por trabalho, causando, assim, desemprego involuntário.

Para os autores da teoria do ajuste via quantidade, contudo, o sistema de preços era incapaz de fornecer todas as informações necessárias ao marketing clerring, isto porque os custos da informação em períodos de desequilíbrio seriam muito altos.

20 "Lef us then assume that households wich do no succeed in buying all the commodities they want at the existing price level use part of their resulting excess purshasing power to bid up the price of bonds as well as commodities. Similarly, firms wich do not succeed in selling all the bonds..." (Patinkin: 1965, p. 235). 
Uma vez acontecido o desequilíbrio, as demandas estimadas pelas firmas perdem sua validade e, com ela, a credibilidade nas informações sobre a demanda. De modo que a demanda se torna pouco conhecida pelos agentes ofertantes.

Conforme Leijonhufvud (1968),

In disequilibrium, it's hard to see how it can be argued that selers in atomistic markets have simpler information problems than the monopolistic. $[. .$.$] the reason is not that sellers in such markets$ have better information or need less information, but that their information costs are very high. [...] Welfare theorists have devoted less energy to the problem of the efficiency of the adjustment processes characterizing alternative structures.

Portanto, ao contrário da defesa da Síntese Neoclássica, para os pensadores do ajuste pelas quantidades o sistema de preços não seria capaz de promover o marketing clearing automaticamente não porque haveria rigidezes no sistema econômico, mas por sua própria incapacidade de refletir todas as informações necessárias a ele.

Uma vez que negam o entendimento do sistema de preços como ajustador - junto à negação da existência de informações perfeitas - abandonam o esquema walrasiano de equilíbrio geral e simultâneo. $O$ processo que se segue ao desequilíbrio, conseqüentemente, é diverso para Leijonhufvud daquele que considera a Síntese Neoclássica. Contudo, a abordagem desequilibista continua sendo de equilíbrio geral, desta feita tomando as variações de quantidades como mecanismo ajustador, à frente do sistema de preços. Para o entendimento disto, é fundamental a distinção entre uma economia monetária e uma economia de troca (Lima: 1992, p. 77).

Havendo desequilíbrio, a demanda potencial pelos produtos das firmas não são manifestas aos empresários, porque os desempregados que desejam trabalhar não demandam produto enquanto estão demandando moeda. Uma vez que os ofertantes decidem as quantidades a ser produzidas com base nas informações correntes, sem tais sinais com relação ao produto, os empresários não se se- 
riam estimulados a absorver o excesso de oferta de trabalho. A diminuição das quantidades seria seguida, portanto de capacidade ociosa. O desemprego involuntário e o acúmulo de estoques exerceriam, em determinado momento das decisões dos empresários, pressão para a retomada do investimento, que desencadeariam uma onda de ajustes de quantidades. Por conta da consideração acima sobre a oferta de trabalho por parte dos desempregados involuntariamente omitindo sinais de demanda pelas mercadorias, os preços variariam mais rapidamente apenas em função das variações a maior das quantidades.

O processo de ajustamento, aqui, consiste na consideração de fundamentos microeconômicos na análise macroeconômica na forma de funções comportamentais, combinada com os conceitos ex-ante e ex-post em um ambiente de trocas no qual a economia acaba se reajustando após um desequilíbrio qualquer de oferta e demanda. Nisto não parece se diferenciar do sistema de Patinkin. A diferenciação, à luz da consideração da ineficácia do sistema de preços, está na consideração de que os agentes econômicos expressariam suas ofertas e demandas no mercado em termos das quantidades desejadas (ex-ante) ajustando-as à medida que se dessem as negociações durante as trocas e incorporando em seus cálculos as restrições de mercado, o que se manifestaria em variações posteriores de preços e tomaria uma dinâmica de um "efeito crowding $o u t$ ", ao final do qual, a economia acabaria atingindo um ponto de equilíbrio que não necessariamente coincidiria com o do equilíbrio walrasiano de longo prazo. Contudo, com uma sucessão de reajustes, essa economia tederia ao mesmo equilíbrio walrasiano de longo prazo.

Semelhantemente ao que acontece na Síntese Neoclássica, a teoria keynesiana no modelo de ajustamento pelas quantidades acabaria sendo restringida a um aspecto da análise - referente ao "curto prazo" - denotada como um momento da tendência maior de equilíbrio de longo prazo ${ }^{21}$. Com isso, o tratamento keynesiano

${ }^{21}$ Contudo, como observa Tadeu Lima (1992, p. 28) Keynes duvidara de tal inevitabilidade, pois quando mesmo adotando a hipótese tradicional de flexibilidade de preços e salários concluíra que o equilibrio geral de pleno emprego não seria necessariamente seu resultado. 
continuaria circunscrito à convivência com a teoria neoclássica, e mais uma vez visto sob a ótica do equilíbrio geral, mesmo que agora o tratamento esteja voltado para o aspecto de desequilíbrio.

\section{CONSIDERAÇõEs FinaIs.}

As abordagens da teoria de Keynes que departamentalizam a economia ou que tratam da deficiência do sistema de preços como mecanismo ajustador do mercado, têm em comum a concepção de que o sistema econômico é capaz por sí só, de imprimir uma inevitabilidade à economia com respeito ao equilíbrio no curto e médio prazos e, no longo prazo, ao equilíbrio de pleno-emprego. Ao fazerem isto invertem o eixo das proposições centrais de Keynes, que equilíbrios abaixo do pleno-emprego são mais plausíveis de serem considerados para as economias capitalistas, concomitantemente, o desequilíbrio não tem uma tendência de se ajustar, caso não haja intervenção no sentido do planejamento e controle capitalista da economia.

Esta, que pode ser considerada a discrepância de fundo entre a teoria de Keynes e as abordagens que tratamos dela, é acompanhada de divergências teóricas e metodológicas deixadas ao longo da compressão efetuada pelos teóricos da Síntese e os do ajustamento pelas quantidades, durante suas adaptações das proposições de Keynes.

A adoção feita pela Síntese do intermediário walrasiano (auctioneer), quando da consideração do marketing clearing, e do tâtonnement nas seguidas variações nas quantidades acompanahdas tardiamente pelos preços, privilegiam uma economia de trocas, em detrimento das proposições sugeridas por Keynes na sua teoria da moeda, ao enfatizar o caráter financeiro prevalecente na demanda monetária, à medida que submetem o financiamento do consumo e da especulação ao financiamento produtivo, subvertendo, assim, a determinação da demanda sobre a atividade econômica - tão cara para a teoria da moeda de Keynes - à dinâmica produtiva, privilegiando, assim, a oferta.

Essas abordagens da teoria de Keynes, ao enfatizarem o equi- 
líbrio e o ajustamento, embora tentem fugir dos cânones neoclássicos, apontam para uma representação da economia que está presente nas abordagens neoclássicas da atividade econômica e não está na de Keynes, qual seja a de forças autônomas de ajustamento. Tal visão não está presente na teoria de Keynes não por acaso, ou por especificidades do problema, como os autores das correntes tratadas defendem, mas porque a instabilidade é algo inerente à economia capitalista. Keynes sabia disso. Os autores da Síntese e do ajustamento pelas quantidades fizeram questão de subestimar ou ignorar tal fato.

\section{REFERÊNCIAS BIBLIOGRÁFICAS}

CHICK, Victoria. Macroeconomia Após Keynes. Rio de Janeiro: Forense Universitária, 1993.

FRANCO, Gustavo H. B. Uma Introdução ao Artigo "O Sr. Keynes e os Clássicos": uma sugestão de interpretação" de J. R. Hicks. In Clássicos da Literatura Econômica, Rio de Janeiro: IPEA/INPES, 1988.

HICKS, John Richard. Valor e Capital. 2. ed. São Paulo: Nova Cultural, 1987.

O Sr. Keynes e os Clássicos: uma sugestão de interpretação. In Clássicos da Literatura Econômica. Rio de Janeiro: IPEA/INPES, 1988.

KEYNES, John Maynard. A Teoria Geral do Emprego, do Juro e da Moeda. São Paulo: Atlas, 1982.

LEIJONHUFVUD, Axel. On Keynesian Economics and the Economics of Keynes. New York: Oxford University Press, 1968.

LIMA, Gilberto Tadeu. Em Busca do Tempo Perdido: a recuperação póskeynesiana da economia do emprego de Keynes. $16^{\circ}$ Prêmio BNDES de Economia. Rio de Janeiro: 1992.

PATINKIN, Don. Money, Interest and Prices. 2. ed. New York: Harper \& Row, 1965.

SANTOS, Robério Ferreira dos. Equilíbrio e Expectativas em Keynes. In Economia Ensaios. vs. 6 e 7. $\mathrm{n}^{\mathrm{\alpha s} .} 2$ e 1. Uberlândia: Departamento de Economia, 1992. 
A Revista Raízes agradece a colaboração dos pareceristas ad hoc a seguir listados, que muito cuidadosamente apreciaram os artigos a ela encaminhados.

Antônio Gomes - Antonio Ildefonso de.A. Melo - Cláudio A. V. Cavalcanti - Deolinda de S. Ramalho - Edgard A. Malagodi Elizabeth C. de A. Lima - Fábio Freitas - Fernando Garcia de Oliveira - Ghislaine Duqué - João Otávio P. de Barros - José H. Rota - Josemir Camilo de Melo • Jurandir A. Xavier • Lilian Letelier Vásquez - Manoel L. Malagutti - Maria Cristina de M. Marin - Maria Lúcia Gonçalves de C. Norma M. de Soler Reinaldo A. Carcanholo • Renato Kilpp Ubiracy de S. Braga 


\section{AOS COLABORADORES}

\section{(NORMAS RELATIVAS ÀS CONTRIBUIÇÕES ENCAMINHADAS PARA}

PuBLICAÇÃO)

1. A revista Raízes aceita trabalhos originais ou trabalhos inéditos em língua portuguesa sob a forma de artigos, ensaios ou resenhas cuja abordagem assista ao seu interesse temático editorial.

2. Os textos deverão ser enviados em disquete flexível de computador padrão IBM-PC, junto à cópia impressa, utilizando-se os programas de edição de texto Word, WordPerfect ou WordStar para Windows e Dos.

3. Pede-se que os textos sejam marginados à esquerda, digitados em espaço duplo e aproximadamente 30 linhas de 65 toques por página, não contendo marcações.

4. Os seguintes itens devem ser observados na realização dos textos:

- aspas simples para palavras com emprego não convencional

- aspas duplas para citações

- itálico para palavras estrangeiras, neologismos e títulos de obras e publicações

- bold para termos a destacar - deve ser usado com parcimônia

- as notas devem ser sempre de pé de página, numeradas correlativamente, e nelas deverão estar incluídas todas as referências bibliográficas (não há, pois, bibliografia).

5. Referências bibliográficas obedecerão ao seguinte critério:

- LTVRO - nome do autor, título do livro (itálico), local de publicação, editora, data de publicação, número(s) da(s) página(s)

- ARTIGO - nome do autor, título do artigo, nome do periódi. co(itálico), volume e número do periódico, data de publicação, número(s) da(s) página(s)

- Obs.: só devem ser inseridas na bibliografia as referências citadas no texto. 
6. Os artigos deverão conter até 25 laudas, os ensaios 15 laudas e as resenhas de livros não devem exceder duas páginas.

7. Cada artigo deverá se fazer acompanhar, necessariamente:

a) do respectivo resumo (português, inglês ou francês) de, no máximo, 10 linhas.

b) dos dados sobre o autor (função atual, cargo que ocupa, vínculo institucional, endereço, telefone, últimas publicações e, quando existentes, o número de fax e endereço eletrônico/Bitnet ou Internet). Não deverão os dados sobre o autor ultrapassar 5 linhas.

8. A publicação dos trabalhos está condicionada a pareceres $a d$ hoc de membros do Conselho Editorial e do Conselho Consultivo. Eventuais sugestões de modificação de estrutura ou conteúdo por parte da Editoria serão efetivadas em consenso com o autor.

9. A redação comunicará aos autores a decisão sobre a publicação ou não dos trabalhos. Em nenhum dos casos haverá a devolução dos originais.

10. Aos autores serão distribuídos 3 (três) exemplares do número da revista que publicar seus trabalhos.

CALENDÁRIO EdTTORIAL PERMANENTE

\begin{tabular}{|c|l|}
\hline Mês & \multicolumn{1}{|c|}{ Atividade } \\
\hline Jan. & \\
\hline Fev. & \\
\hline Mar. & Início período letivo / Fechamento recepção de artigos \\
\hline Abr. & Pareceres \\
\hline Mai. & Editoração / Gráfica \\
\hline Jun. & Lançamento \\
\hline Jul. & \\
\hline Ago. & Início período letivo \\
\hline Set. & Fechamento recepção de artigos \\
\hline Out. & Pareceres \\
\hline Nov. & Editoração / Gráfica \\
\hline Dez. & Lançamento \\
\hline
\end{tabular}

